Agrotrópica 30(1): 49 - 56. 2018.

Centro de Pesquisas do Cacau, Ilhéus, Bahia, Brasil

\title{
VARIABILIDADE GENÉTICA DE CULTIVARES E HÍBRIDOS ELITE DE MANGUEIRA COM BASE EM MARCADORES MOLECULARES
}

\author{
João Pedro Basso', Fábio Gelape Faleiro², Jamile da Silva Oliveira ${ }^{3 *}$, Tadeu Graciolli \\ Guimarães $^{2}$, Marcelo Fideles Braga ${ }^{2}$, Kenia Gracielle da Fonseca ${ }^{3}$, Nilton Tadeu Vilela \\ Junqueira ${ }^{2}$, Francisco Pinheiro Lima Neto ${ }^{4}$
}

\begin{abstract}
${ }^{1}$ União Pioneira de Integração Social, BR-20, km 12, 73300-001, Planaltina, DF; jotapbasso@gmail.com. ${ }^{2}$ Embrapa Cerrados, BR 020, km 18, Rodovia Brasília/Fortaleza, 73310-970, Planaltina, DF; fabio.faleiro@embrapa.br; tadeu.graciolli@embrapa.br; marcelo.fideles@embrapa.br; nilton.junqueira@embrapa.br. ${ }^{3}$ Universidade de Brasília, Campus Universitário Darcy Ribeiro, Asa Norte, 70910-900, Brasília, DF, jamile.oliveira54@ gmail.com, kenia.gfonseca@gmail.com. ${ }^{4}$ Embrapa Semiárido, Rodovia BR-428, km 152, Zona Rural - C.P. 23, 56302-970, Petrolina, PE, pinheiro.neto@embrapa.br.
\end{abstract}

*Autor para correspondência: jamile.oliveira54@gmail.com

A cultura da manga (Mangifera indica L.) possui grande importância social e econômica no Brasil. Entretanto, os cultivos comerciais são baseados apenas nas cultivares Tommy Atkins e Palmer, sendo necessário o aumento da base genética por meio da disponibilidade de novas cultivares superiores. Neste trabalho, objetivou-se verificar a variabilidade genética molecular de 15 cultivares e híbridos elite de manga avaliados no Ensaio Nacional de Cultivares, utilizando marcadores moleculares RAPD e ISSR. O DNA genômico das 15 plantas foi extraído e amplificado via Reação em Cadeia Polimerase, utilizando-se 10 primers para RAPD e 7 para ISSR. Foram obtidos 150 marcadores RAPD e 135 marcadores ISSR, os quais foram codificados em dados binários. Foi calculada uma matriz de dissimilaridade genética, a partir da qual foram realizadas as análises de agrupamento e dispersão gráfica. Pela análise de agrupamento e dispersão gráfica foi possível observar a variabilidade genética entre os materiais. A cultivar "Rosa 2" e o "híbrido 263/99" foram os que apresentaram maior dissimilaridade genética, sendo alternativas para ampliar a base genética das atuais cultivares de manga utilizadas pelos fruticultores. Os marcadores moleculares RAPD e ISSR foram úteis e complementares para o estudo da variabilidade genética das cultivares e híbridos de manga.

Palavras-chave: Mangifera indica L., vulnerabilidade genética, melhoramento genético, cultivar.

\section{Genetic variability of cultivars and elite hybrids of mango tree based on} molecular markers. The mango tree (Mangifera indica L.) has a great social and economic importance in Brazil. However, commercial crops are based only on Tommy Atkins and Palmer cultivars, and it is necessary to increase the genetic base through the availability of new superior cultivars. The objective of this work was to verify the molecular genetic variability of 15 elite cultivars and hybrids evaluated in the National Cultivars Assay, using RAPD and ISSR molecular markers. Genomic DNA from the 15 plants was extracted and amplified via Polymerase Chain Reaction, using 10 RAPD primers and 7 ISSR primer. We obtained 150 RAPD markers and 135 ISSR markers, which were encoded in binary data. A genetic dissimilarity matrix was calculated, from which the analyzes of grouping and graphic dispersion were performed. By the analysis of grouping and dispersion graphic it was possible to observe the genetic variability among the cultivars and hybrids. "Rosa 2 " and "263/99 hybrids" were the ones that presented the greatest genetic dissimilarity, being alternatives to expand the genetic base of the current mango cultivars used by fruit growers. RAPD and ISSR molecular markers were useful and complementary to the study of the genetic variability of mango cultivars and hybrids.

Key words: Mangifera indica L., genetic vulnerability, genetic improvement, cultivar. 


\section{Introdução}

A mangueira (Mangifera indica L.) é uma espécie originária da parte oriental da Índia (Duval et al., 2005), sendo um dos mais apreciados frutos de origem tropical. O processo de disseminação da cultura foi lento, uma vez que a espécie alcançou outras terras somente depois de ter sido cultivada há mais de 4 séculos em suas regiões de origem. A disseminação da cultura pelo mundo foi iniciada com a descoberta das rotas comerciais marítimas entre Europa e Ásia no início do século 16. Os portugueses foram os que executaram esse deslocamento, primeiramente levando as costas da África e depois para a América. A manga foi introduzida no Brasil por volta de 1700 (Souza et al., 2002).

O Brasil está entre os dez principais países produtores de manga com uma área superior a $70 \mathrm{mil}$ hectares e produção de aproximadamente 1.132.000 toneladas (Anuário Brasileiro da Fruticultura, 2016). A mangueira possui grande importância social e econômica no Brasil, entretanto os cultivos comerciais são baseados apenas nas cultivares Tommy Atkins e Palmer, quase totalmente visando o consumo in natura.

Com a pouca diversidade de mangas em pomares comerciais no Brasil, é necessário o aumento da base genética por meio da disponibilidade de novas cultivares superiores. Para tanto, o melhoramento genético da manga tem sido realizado por diversas instituições nacionais e internacionais com diferentes estratégias para atender a dinâmica do mercado (Pinto, 1996; Rossetto et al., 1996; Brettell et al., 2004; Human et al., 2009). A Embrapa e parceiros possuem um programa de melhoramento genético da mangueira, $o$ qual tem desenvolvido diferentes cultivares e híbridos elite que estão sendo avaliados com base em características agronômicas em diferentes regiões do Brasil, por meio do Ensaio Nacional de Cultivares. O conhecimento da variabilidade genética desses materiais genéticos é importante e pode ser um critério a mais para o lançamento de novas cultivares.

Marcadores moleculares do DNA têm sido utilizados como ferramentas auxiliares nas diferentes etapas do melhoramento genético, desde a caracterização do germoplasma até as etapas finalísticas de desenvolvimento e seleção de plantas melhoradas. A capacidade dos marcadores moleculares de analisar genomas de interesse de forma ampla, sem influência do ambiente, permite gerar informações precisas sobre a variabilidade genética complementando outras informações obtidas com base em dados de pedigree e de características morfológicas e agronômicas (Faleiro, 2011). Assim, objetivou-se avaliar e quantificar a variabilidade genética de cultivares e híbridos elite de mangueira avaliados no Ensaio Nacional de Cultivares, com base em marcadores moleculares RAPD e ISSR, visando analisar a base genética de potenciais cultivares geneticamente superiores.

\section{Material e Métodos}

A caracterização molecular das 15 cultivares e híbridos elite de mangueira foi realizada utilizando marcadores RAPD e ISSR no Laboratório de Genética e Biologia Molecular da Embrapa Cerrados, Planaltina, DF. As cultivares e híbridos elite avaliados foram: BRS Roxa 141 (Amrapali x Tommy Atkins), CPAC 329/94, BRS Lita (Amrapali x Tommy Atkins), CPAC 165/93, CPAC 58/95, Rosa 36, BRS Beta (Amrapali x Winter), Tommy Atkins, BRS Alfa 142 (Mallika x Van Dyke), Palmer, Rosa 46, BRS Ômega (Amrapali x Van Dyke), CPAC 22/93, Rosa 2 e CPAC 263/94.

O DNA genômico de cada material foi extraído a partir do tecido foliar em estágio intermediário de maturação, utilizando o método do CTAB, com modificações (Faleiro et al., 2003). A quantificação foi realizada utilizando o equipamento Nanodrop e as amostras de DNA de cada acesso foram diluídas para 10 çg/ì L.

O DNA de cada material genético foi amplificado para obtenção de marcadores RAPD. As reações de amplificação foram feitas em um volume total de 13 $\mu \mathrm{L}$, contendo Tris- $\mathrm{HCl} 10 \mathrm{mM}$ (pH 8,3), $\mathrm{KCl} 50 \mathrm{mM}$, $\mathrm{MgCl} 23 \mathrm{mM}, \quad 100 \mu \mathrm{M}$ de cada um dos desoxiribonucleotídios (dATP, dTTP, dGTP e dCTP), $0,4 \mu \mathrm{M}$ de um primer (Operon Technologies Inc., Alameda, CA, EUA), uma unidade da enzima Taq polimerase e, aproximadamente, 15 çg de DNA.

Para obtenção dos marcadores RAPD, foram utilizados dez primers decâmeros OPD (07 e 10), OPE (16 e 18), OPF (17), OPG (01, 05, 08 e 17) e OPH (4) 
Variabilidade genética de mangueira

Tabela 1 - Primers RAPD e ISSR utilizados e bandas polimórficas (BP) e monomórficos (BM), Embrapa Cerrados,

\begin{tabular}{|c|c|c|c|c|c|}
\hline \multirow{2}{*}{ Primers } & \multicolumn{2}{|c|}{ RAPD } & \multirow{2}{*}{ Primers } & \multicolumn{2}{|c|}{ ISSR } \\
\hline & $\mathrm{BP}$ & $\mathrm{BM}$ & & $\mathrm{BP}$ & $\mathrm{BM}$ \\
\hline OPF01- ACGGATCCTG & 11 & 5 & 05- AGCAGCAGCAGCAGC & 15 & 5 \\
\hline OPH12- ACGCGCATGT & 19 & 1 & 06- AGGAGGAGGAGGAGG & 17 & 1 \\
\hline OPE16- GGTGACTGTG & 10 & 2 & 07- CAGCAGCAGCAGCAG & 25 & 6 \\
\hline OPD04- TCTGGTGAGG & 14 & 3 & 08- CGAGAGAGAGAGAGA & 15 & 4 \\
\hline OPD07- TTGGCACGGG & 17 & 2 & 13- GAGAGAGAGAGAGAG & 16 & 2 \\
\hline OPE20- AACGGTGACC & 16 & 1 & 14- AGAGAGAGAGAGAGA & 13 & 3 \\
\hline OPE18- GGACTGCAGA & 5 & 5 & 15- GTGTGTGTGTGTGTGT & 10 & 3 \\
\hline OPG08- TCACGTCCAC & 8 & 4 & & & \\
\hline OPH08- GAAACACCCC & 9 & 4 & & & \\
\hline OPG05- CTGAGACGGA & 13 & 0 & & & \\
\hline Total & 122 & 27 & Total & 111 & 24 \\
\hline
\end{tabular}

(Tabela 1). As amplificações foram efetuadas em termociclador programado para 40 ciclos, cada um constituído pela seguinte sequência: 15 segundos a $94{ }^{\circ} \mathrm{C}, 30$ segundos a $35^{\circ} \mathrm{C}$ e 90 segundos a $72{ }^{\circ} \mathrm{C}$. Após os 40 ciclos, foi feita uma etapa de extensão final de seis minutos a $72{ }^{\circ} \mathrm{C}$, e finalmente, a temperatura foi reduzida para $4{ }^{\circ} \mathrm{C}$.

Para marcadores ISSR, o DNA foi amplificado utilizando-se sete primers (ISSR-5, ISSR-6, ISSR-7, ISSR-8, ISSR-13, ISSR-14 e ISSR-15) (Tabela 1) e a seguinte reação: 20çg de DNA genômico, 1 unidade de Taq DNA polimerase, $0,3 \mu \mathrm{M}$ de primer e água até completar um volume de 13 ì l. As amplificações foram efetuadas em termociclador programado por 5 minutos a $94{ }^{\circ} \mathrm{C}, 35$ ciclos cada um constituído pela seguinte sequencia: 40 segundos a $94^{\circ} \mathrm{C}, 40$ segundos a $48^{\circ} \mathrm{C}$ e 1 minuto a $72{ }^{\circ} \mathrm{C}$. Após os 35 ciclos, foi feita uma etapa de extensão final de dois minutos a $72{ }^{\circ} \mathrm{C}$, e finalmente, a temperatura foi reduzida para $4{ }^{\circ} \mathrm{C}$.

Após as amplificações via RAPD e ISSR, adicionou-se a cada amostra, $3 \mu \mathrm{l}$ de uma mistura de azul de bromofenol $(0,25 \%)$ e glicerol $(60 \%)$ em água. Essas amostras foram aplicadas em gel de agarose $(1,2 \%)$, corado com brometo de etídio, submerso em tampão TBE (Tris-Borato $90 \mathrm{mM}$, EDTA $1 \mathrm{mM}$ ). A separação eletroforética foi de, aproximadamente, quatro horas, a 90 volts. Ao término da corrida, os géis foram fotografados sob luz ultravioleta.

Os marcadores RAPD e ISSR gerados foram convertidos em uma matriz de dados binários, a partir da qual foram estimadas as distâncias genéticas entre as cultivares, com base no complemento do coeficiente de similaridade de Nei e Li, com o auxílio do Programa Genes (Cruz, 2013). A partir das matrizes de distâncias genéticas foram realizadas análises de agrupamento e dispersão gráfica baseada em escalas multidimensionais usando o método das coordenadas principais, com auxílio do Programa SAS (Sas Institute Inc., 2004) e Statistica (Statsoft Inc., 2005).

\section{Resultados e Discussão}

Com base nas análises realizadas por meio das técnicas moleculares, obteve-se um total de 149 marcadores RAPD para os 15 cultivares e híbridos de M. indica, sendo que desse total, 122 foram polimórficos e 27 monomórficos. Os primers que revelaram um maior polimorfismo foram: OPH12 com 19 marcadores polimórficos e 1 marcador monomórfico; OPE20 com 16 marcadores polimórficos e 1 marcador monomórfico; e OPG5 com 13 marcadores polimórficos e nenhum marcador monomórfico (Tabela 1).

Com relação aos marcadores ISSR, foram obtidos um total de 135 marcadores, sendo que 111 foram polimórficos e 24 monomórficos (Tabela 1). Os primers que revelaram um maior polimorfismo foram: ISSR6 com 17 marcadores polimórficos e um marcador monomórfico; e ISSR13 com 16 marcadores polimórficos e 2 marcadores monomórficos.

Por meio da estimativa das distâncias genéticas entre as cultivares e híbridos de $M$. indica obtidas com base em marcadores RAPD, observou-se valores que variaram de 0,18 a 0,54 (Tabela 2). A amplitude 
Tabela 2 - Matriz de dissimilaridade genética entre 15 cultivares e híbridos elite de mangueira, calculadas com base em 149 marcadores moleculares RAPD. Embrapa Cerrados, 2017

\begin{tabular}{|c|c|c|c|c|c|c|c|c|c|c|c|c|c|c|}
\hline Acessos & 2 & 3 & 4 & 5 & 6 & 7 & 8 & 9 & 10 & 11 & 12 & 13 & 14 & 15 \\
\hline 1 & 0,39 & 0,28 & 0,29 & 0,36 & 0,24 & 0,21 & 0,16 & 0,29 & 0,54 & 0,28 & 0,21 & 0,18 & 0,44 & 0,48 \\
\hline 2 & & 0,33 & 0,37 & 0,37 & 0,43 & 0,36 & 0,38 & 0,42 & 0,52 & 0,37 & 0,39 & 0,35 & 0,46 & 0,49 \\
\hline 3 & & & 0,30 & 0,36 & 0,27 & 0,27 & 0,25 & 0,36 & 0,54 & 0,28 & 0,23 & 0,28 & 0,47 & 0,53 \\
\hline 4 & & & & 0,34 & 0,32 & 0,27 & 0,25 & 0,28 & 0,52 & 0,32 & 0,24 & 0,27 & 0,50 & 0,49 \\
\hline 5 & & & & & 0,43 & 0,34 & 0,35 & 0,35 & 0,54 & 0,38 & 0,37 & 0,41 & 0,51 & 0,54 \\
\hline 6 & & & & & & 0,21 & 0,27 & 0,34 & 0,51 & 0,18 & 0,22 & 0,29 & 0,33 & 0,48 \\
\hline 7 & & & & & & & 0,20 & 0,34 & 0,48 & 0,25 & 0,22 & 0,25 & 0,42 & 0,47 \\
\hline 8 & & & & & & & & 0,35 & 0,51 & 0,27 & 0,24 & 0,30 & 0,49 & 0,48 \\
\hline 9 & & & & & & & & & 0,50 & 0,25 & 0,26 & 0,32 & 0,41 & 0,47 \\
\hline 10 & & & & & & & & & & 0,24 & 0,26 & 0,24 & 0,21 & 0,28 \\
\hline 11 & & & & & & & & & & & 0,21 & 0,31 & 0,38 & 0,51 \\
\hline 12 & & & & & & & & & & & & 0,23 & 0,42 & 0,53 \\
\hline 13 & & & & & & & & & & & & & 0,40 & 0,50 \\
\hline 14 & & & & & & & & & & & & & & 0,34 \\
\hline
\end{tabular}

1. BRS Roxa 141, 2. CPAC 329/94, 3. BRS Lita, 4. CPAC 165/93, 5. CPAC 58/95, 6. Rosa 36, 7. BRS Beta, 8. Tommy Atkins, 9. BRS Alfa, 10. Palmer, 11. Rosa 46, 12. BRS Ômega, 13. CPAC 22/93, 14. Rosa 2, 15. CPAC 263/94.

das distâncias genéticas estimadas indicam a existência de grande variabilidade entre as cultivares e híbridos elite de M.indica avaliados. A menor distância genética foi obtida entre a cultivar BRS Roxa 141 e o acesso CPAC 22/93 e as maiores distâncias genéticas $(0,54)$ entre as cultivares BRS Roxa e Palmer; BRS Lita e Palmer; híbrido 58/95 e Palmer e híbridos CPAC 58/95 e CPAC 263/94.

Os valores das distâncias genéticas obtidas entre os 15 acessos de $M$. indica, com base em marcadores ISSR variaram de 0,10 a 0,60 (Tabela 3 ). As distâncias máximas estimadas foram entre os híbridos CPAC 58/95 e CPAC 263/94 $(0,60)$ e entre os híbridos CPAC 165/93 e CPAC 263/94 (0,57). A amplitude de valores de distância genética evidencia a análise de acessos com diferentes graus de dissimilaridade, como também foi verificado em outras coleções avaliadas com base em marcadores ISSR (Rocha et al., 2012).

Os marcadores moleculares RAPD e ISSR evidenciaram as distâncias genéticas entre as cultivares e híbridos elite, os quais mostram a variabilidade que pode ser usada para trabalhos de melhoramento, com o objetivo de diminuir a vulnerabilidade das cultivares à fatores bióticos $\mathrm{e}$ abióticos. A amplitude de valores também foi verificada em outras coleções avaliadas com base em marcadores RAPD por Ordon et al. (1997) e
Todorovska et al. (2003). Ravishankar et al. (2015) e Ravishankar et al. (2011) desenharam primes SSRs e estimaram a diversidade genética de mangueira. Santos et al. (2008) estimaram a similaridade genética de acessos de mangueira de diferentes origens geográficas utilizando marcadores do tipo AFLP.

A partir das matrizes de dissimilaridade genética, foram realizadas as análises de agrupamento e dispersão gráfica. Pelas análises de agrupamento e dispersão gráfica obtidas com base nos marcadores RAPD (Figura 1), foi possível observar diferentes grupos de similaridade e a variabilidade genética das cultivares e híbridos elite de $M$. indica em relação à cultivar Tommy Atkins, os quais são alternativas para ampliar a base genética das atuais cultivares de manga utilizadas pelos fruticultores. Adotando-se como ponto de corte a distância genética média de 0,35; observa-se a formação de quatro grupos de similaridade. O grupo um foi formado pela maioria das cultivares e híbridos de $M$. indica e os demais genótipos ficaram sozinhos, com exceção das cultivares Palmer e Rosa 2, que se mantiveram próximas, formando um segundo grupo de similaridade. Os acessos CPAC 329/94, CPAC 58/ 95 e CPAC 263/94 ficaram isolados dos demais acessos, apresentando maiores dissimilaridades genéticas em relação aos demais genótipos. Pode-se 
Tabela 3 - Matriz de dissimilaridade genética entre 15 cultivares e híbridos elite de mangueira, calculadas com base em 135 marcadores moleculares ISSR. Embrapa Cerrados, 2017

\begin{tabular}{|c|c|c|c|c|c|c|c|c|c|c|c|c|c|c|}
\hline Acessos & 2 & 3 & 4 & 5 & 6 & 7 & 8 & 9 & 10 & 11 & 12 & 13 & 14 & 15 \\
\hline 1 & 0,26 & 0,28 & 0,37 & 0,47 & 0,33 & 0,25 & 0,22 & 0,27 & 0,20 & 0,20 & 0,20 & 0,22 & 0,53 & 0,48 \\
\hline 2 & & 0,20 & 0,32 & 0,40 & 0,38 & 0,31 & 0,31 & 0,27 & 0,27 & 0,31 & 0,28 & 0,28 & 0,55 & 0,54 \\
\hline 3 & & & 0,30 & 0,33 & 0,32 & 0,29 & 0,26 & 0,22 & 0,29 & 0,29 & 0,31 & 0,32 & 0,55 & 0,50 \\
\hline 4 & & & & 0,37 & 0,37 & 0,35 & 0,36 & 0,33 & 0,37 & 0,39 & 0,38 & 0,43 & 0,49 & 0,57 \\
\hline 5 & & & & & 0,40 & 0,36 & 0,39 & 0,36 & 0,36 & 0,39 & 0,37 & 0,42 & 0,49 & 0,60 \\
\hline 6 & & & & & & 0,31 & 0,26 & 0,32 & 0,25 & 0,23 & 0,28 & 0,33 & 0,43 & 0,47 \\
\hline 7 & & & & & & & 0,16 & 0,23 & 0,17 & 0,24 & 0,25 & 0,28 & 0,55 & 0,47 \\
\hline 8 & & & & & & & & 0,23 & 0,16 & 0,15 & 0,18 & 0,22 & 0,54 & 0,47 \\
\hline 9 & & & & & & & & & 0,25 & 0,23 & 0,26 & 0,29 & 0,51 & 0,49 \\
\hline 10 & & & & & & & & & & 0,10 & 0,18 & 0,23 & 0,55 & 0,47 \\
\hline 11 & & & & & & & & & & & & 0,23 & 0,52 & 0,47 \\
\hline 12 & & & & & & & & & & & & 0,12 & 0,53 & 0,45 \\
\hline 13 & & & & & & & & & & & & & 0,54 & 0,48 \\
\hline 14 & & & & & & & & & & & & & & 0,48 \\
\hline
\end{tabular}

1. BRS Roxa 141, 2. CPAC 329/94, 3. BRS Lita, 4. CPAC 165/93, 5. CPAC 58/95, 6. Rosa 36, 7. BRS Beta, 8. Tommy Atkins, 9. BRS Alfa, 10. Palmer, 11. Rosa 46, 12. BRS Ômega, 13. CPAC 22/93, 14. Rosa 2, 15. CPAC 263/94.
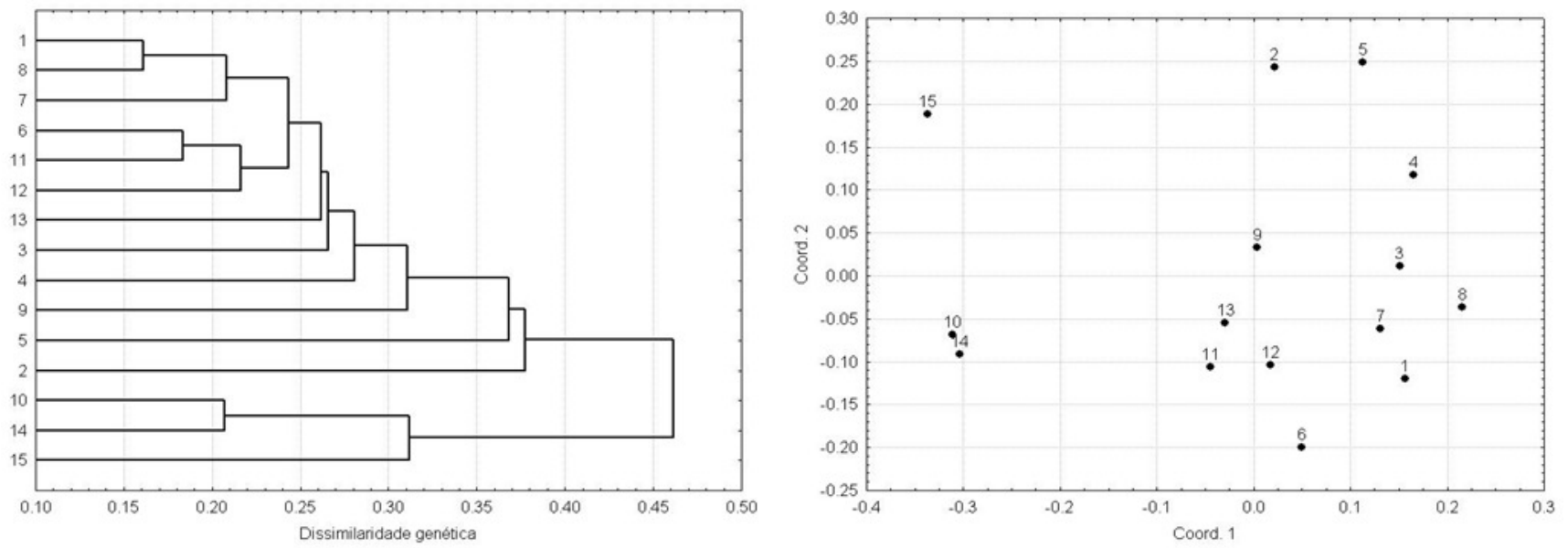

Figura 1 - Análise de agrupamento e dispersão gráfica de 15 acessos de Mangifera indica L., com base na matriz de distâncias genéticas calculadas utilizando-se 150 marcadores RAPD. O método do UPGMA foi usado como critério de agrupamento. Embrapa Cerrados, 2017. Legenda: 1. BRS Roxa 141, 2. CPAC 329/94, 3. BRS Lita, 4. CPAC 165/93, 5. CPAC 58/95, 6. Rosa 36, 7. BRS Beta, 8. Tommy Atkins, 9. BRS Alfa, 10. Palmer, 11. Rosa 46, 12. BRS Ômega, 13. CPAC 22/93, 14. Rosa 2, 15. CPAC $263 / 94$.

observar no maior grupo de similaridade formado, que houve uma variabilidade genética entre os genótipos dentro do grupo.

A variabilidade genética entre as cultivares e híbridos elite de manga também foi verificada com base na análise de agrupamento e o gráfico de dispersão obtidos a partir das distâncias genéticas estimadas, com base nos marcadores ISSR (Figura 2). Na análise de agrupamento, adotando-se como ponto de corte a distância média de 0,3; houve a formação de cinco grupos de similaridade. No primeiro grupo ficaram agrupados a maioria dos genótipos. Assim como verificado com base nos marcadores RAPD, podese verificar a variabilidade genética entre os genótipos dentro desse maior grupo de similaridade. Os acessos CPAC 165/93, CPAC 58/95, Rosa 2 e CPAC 263/94 

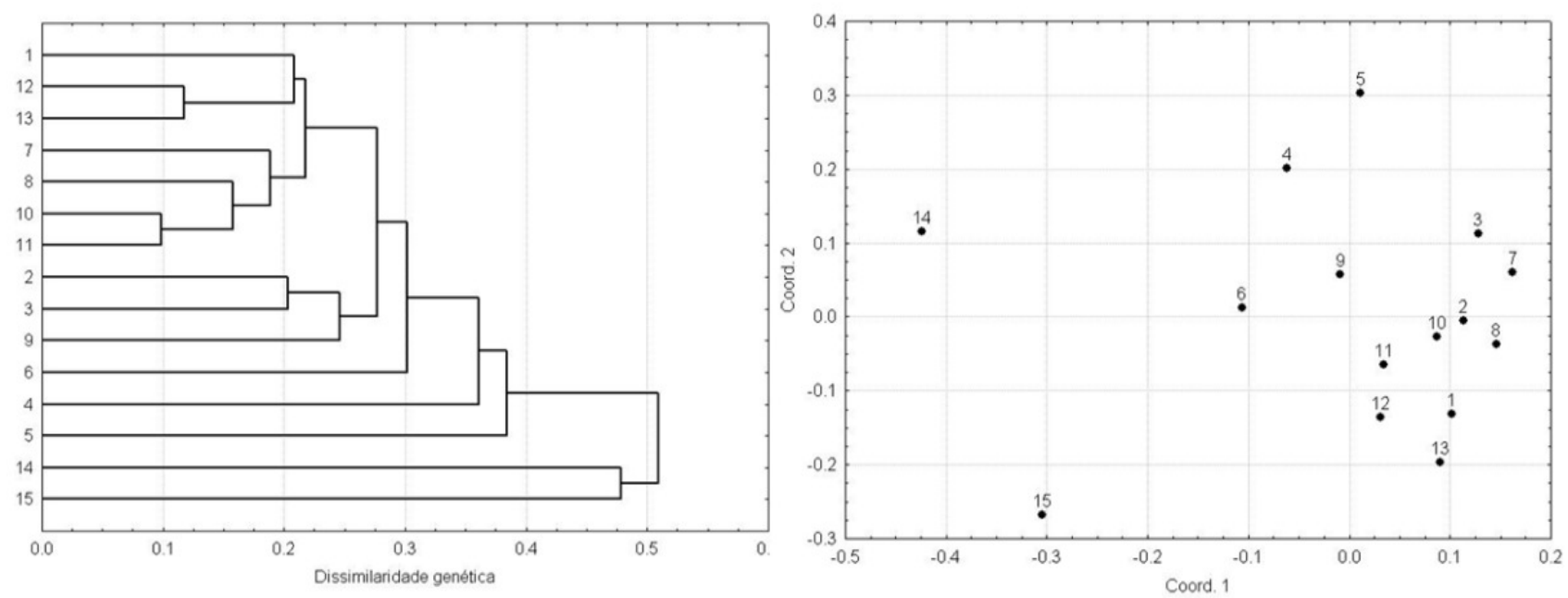

Figura 2 - Análise de agrupamento e dispersão gráfica de 15 acessos de Mangifera indica L., com base na matriz de distâncias genéticas calculadas utilizando-se 135 marcadores ISSR. O método do UPGMA foi usado como critério de agrupamento. Embrapa Cerrados, 2017. Legenda: 1. BRS Roxa 141, 2. CPAC 329/94, 3. BRS Lita, 4. CPAC 165/93, 5. CPAC 58/95, 6. Rosa 36, 7. BRS Beta, 8. Tommy Atkins, 9. BRS Alfa, 10. Palmer, 11. Rosa 46, 12. BRS Ômega, 13. CPAC 22/93, 14. Rosa 2, 15. CPAC 263/94.

se apresentaram em grupos separados na análise de agrupamento, mantendo-se mais distantes no gráfico de dispersão, evidenciando a variabilidade existente entre eles e os demais genótipos analisados no presente trabalho.

Segundo Pinto et al. (2009), os híbridos CPA 263/ 94 e CPAC 58/95 têm peso de fruto entre $300 \mathrm{~g}$ a 450 $\mathrm{g}$, atendendo a faixa de peso do mercado Europeu e da mesma forma do Americano, possuem excelente qualidade de frutos e alto rendimento de polpa, podendo ser consumidas in natura ou processadas, pois têm um elevado teor de sólidos solúveis totais, com alto potencial de lançamento para competir com 'Tommy Atkins' no mercado.

A elevada porcentagem de marcadores polimórficos RAPD e ISSR demonstra a alta variabilidade genética entre as cultivares e híbridos elite de manga obtidos pelo programa de melhoramento genético realizado na Embrapa. Estes genótipos também estão sendo avaliados no Ensaio Nacional de Cultivares da Embrapa para a validação do desempenho agronômico em condições comerciais.

As estimativas de distâncias genéticas entre os genótipos elite de manga obtidas neste trabalho foram semelhantes às estimativas relatadas por Faleiro et al. (2010), que utilizaram marcadores RAPD para caracterizar 28 acessos de mangueira do Banco Ativo de Germoplasma da Embrapa Cerrados, os quais são utilizados como genitores no programa de melhoramento da mangueira na Embrapa.

Os resultados observados no presente estudo evidenciaram a variabilidade existente entre as cultivares e híbridos elite, desenvolvidos pelo programa de melhoramento genético da mangueira na Embrapa. Estes genótipos podem ser utilizados efetivamente nos programas de melhoramento da cultura como fonte de variabilidade e também apresentam grande potencial para a ampliação da base genética das atuais cultivares plantadas comercialmente, as quais podem ser uma alternativa para a diversificação dos pomares de manga no Brasil.

\section{Conclusão}

Os marcadores moleculares RAPD e ISSR são úteis e complementares para o estudo de variabilidade genética das cultivares e híbridos elite de mangueira. Com o uso dos marcadores moleculares é possível observar a dissimilaridade entre as cultivares e híbridos de mangueira analisados neste trabalho, os quais apresentam potencial para o mercado nacional de manga, para diminuir a vulnerabilidade existente nos pomares comerciais. 
A caracterização genético-molecular é importante para o programa de melhoramento genético da mangueira, uma vez que vai complementar os estudos de caracterização agronômica que vão subsidiar o lançamento de novas cultivares e também o uso de novos genitores na base de cruzamentos do programa.

\section{Literatura Citada}

ANUÁRIO BRASILEIRO DE FRUTICULTURA. 2016. Gazeta, Santa Cruz, Rio Grande do Sul. $17 \mathrm{p}$.

BRETTELL, R. I. S. et al. 2004. Inheritance of fruit characters in hybrid mangoes produced through controlled pollination. Acta Horticulturae 645 (91): 319-326.

CRUZ, C. D. 2013. Genes - a software package for analysis in experimental statistics and quantitative genetics. Acta Scientiarum Agronomy (Brasil) 35 (3):271-276.

DUVAL, M. F. et al. 2005. Development of microsatellite markers for mango (Mangifera indica L.). Molecular Ecology Notes 5(4):824826.

FALEIRO, F. G. et al. 2003. Metodologia para operacionalizar a extração de DNA de espécies nativas do cerrado. Planaltina, DF, Embrapa Cerrados. Comunicado Técnico, n.92.

FALEIRO, F. G. et al. 2010. Fingerprinting analysis of mango (Mangifera indica L.) cultivars introduced in Brazil using RAPD markers. Acta Horticulturae 864(91):127-132.

FALEIRO, F. G. 2011. Aplicações de marcadores moleculares como ferramenta auxiliar em programas de conservação, caracterização e uso de germoplasma e melhoramento genético vegetal. In: Faleiro, F. G.; Andrade, S. R. M.; Reis Jr, F. B. eds. Biotecnologia: estado da arte e aplicações na agropecuária. Planaltina, DF, Embrapa Cerrados. pp.55-118.

HUMAN, C. F.; RHEEDER, S.; SIPPEL, A. D. 2009. New cultivars and hybrid selections from the
Mango Breeding Program of the Agricultural Research Council in South Africa. Acta Horticulturae 820(91):119-126.

ORDON, F.; SCHIEMANN, A.; FRIEDT, W. 1997. Assessment of the genetic relatedness of barley accessions (Hordeum vulgares L.) resistant to soil borne mosaic inducing viruse (BaMMV, BaYMV, BaYMV-2) using RAPDs. Theoretical and Applied Genetics 94:325-330.

PINTO, A.C. de Q. 1996. Melhoramento da mangueira (Mangifera indica L.) no ecossistema dos Cerrados do Brasil Central por meio da hibridação. Pesquisa Agropecuária Brasileira 30(3):369-374.

PINTO, A. C. Q. et al. 2009. Performance of Seven New Mango (Mangifera indica L.) Hybrid Selections at the Central Region of Brazil. Acta Horticulturae 1(91):137-145.

RAVISHANKAR, K. V. et al. 2015. Genetic diversity and population structure analyses of mango (Mangifera indica L.) cultivars assessed by microsatellite markers. Trees 29(1):775-783.

RAVISHANKAR, K. V. et al. 2011. Development of new microsatellite markers from mango (Mangifera indica L.) and cross-species amplification. American Journal of Botany 98(1):96-99.

ROCHA, A. et al. 2012. Genetic Diversity of 'Ubá' Mango Tree Using ISSR Markers. Molecular Biotechnology 50(2):108-113.

ROSSETTO, C. J. et al. 1996. Mango breeding for resistance to diseases and pests. Acta Horticulturae 455(95):299-304.

SANTOS, C. A. F. et al. 2008. Similaridade genética de acessos de mangueira de diferentes origens geográficas avaliadas por marcadores AFLP. Revista Brasileira de Fruticultura 30(3):736-740.

SAS INSTITUTE. 2004. SAS user's guide: statistic: version 9.1.3. Cary, SAS Institute, (USA). 846p.

STATSOFT, INC. 2005. Statistica for Windows (data analysis software system), version 7.1.Statsoft, Tulsa, Oklahoma (USA). 
SOUZA, J. da S. et al. 2002. Aspectos socioeconômicos. In: Genú, P. J. de C.; Pinto, A. C.de Q. eds. A cultura da mangueira. Brasília, DF, Embrapa Informação Tecnológica. pp.33-35.
TODOROVSKA, E.; TRIFONOVA, A.; ATANASSOV, A. 2003. Genetic diversity among elite Bulgarian barley varieties evaluated by RFLP and RAPD markers. Euphytica 129(3):325-336. 